\title{
Valor clinico da sôro-reacção de Wassermann
}

\author{
Por Altino Antunes, $4 \cdot^{\circ}$ annista de \\ Medicina.
}

Muitas pessoas e, desgraçadamente, entre ellas, se contam varios clinicos, que querem attribuir á sôro-reacção de Wassermann um valor absoluto, a ponto de mudar de diagnostico, conforme o resultado que lhes ella fornece. Outras pessoas, menos credulas e mais criticas, tendo prazer em negar verdades mais ou menos estąbelecidas, dizem, em face de um resultado negativo da reação de Wassermann, em casos clinicamente de syphilis :... "mas" de que serve esta reação si ella deu resultado negativo e eu tenho a certeza de que se trata de um caso de syphilis?" Outras ainda, mais incredulas, taxam-n-a de alchimia- pura e aconselham fazel-a obedecendo ás leis da magia antiga ou moderna, sorrindo de seus resultados.

Vêdes, pelo exposto, quão varios são os modos de acatar os resultados desta reaç̧ão e quanto exagero ha em todos elles, levados uns, por uma grande dóse de descrença e outros, por uma credulidade á toda prova, tocando, perdoem-me dizel-o, ás raias da ingenuidade.

Não quero e nem é meu intuito vos convencer de que a reacção de Wassermann seja infallivel, pois, si tal tentasse, não procederia com lealdade porque eu mesmo assim não penso; não vos pretendo tambem dizer que a reação de Wassermann carece de valor e que é uma alchimia vestida com modernos trajos, porque, si assim falasse, faltaria com a verdade; quero, apenas, mostrar-vos qual o seu valor real e quaes as indicações que, della, podemos esperar.

A reaç̧ão de Wassermann, como todas as reaç̧ões congeneres, isto é, que têm por base o desvio do complementó, em grande 
parte, depende do organismo, pois, o anticorpo que, com o antigeno, vae fixar o complemento, impedindo a hemolyse se dê, é elaborado pelo organismo que reage á infecção e, como nós não podemos obrigar a todos os organismos reagirem egualmente, obedecendo a leis mathematicas e immutaveis, facilmente se conclúe que um doente póde haver contrahido a infeç̧ão luetica sem apresentar, no seu organismo, vestigios della ou, no seu sangue, os anticorpos especificos que nos vão revelar a existencia da molestia e isto porque, ou o tempo decorrido entre o accidente primario e a occasião em que se examina o doente foi demasiado curto, não sendo ainda possivel o apparecimento das reaç̧ões organicas, ou o organismo reagiu differentemente, não apresentando, como os demais, os signaes que servem ao clinico ou ao analysta para dizer si se trata de iṇfecção hunteriana ou não.

Reproduzo aqui um quadro tirado a Craig, (*) em que vemos que, nos cinco primeiros dias após o accidente primario, a reacção dá resultado negativo e, nos dias successivos, até o trigesimo, varia de 3 a $20 \%$ de resultados positivos.

\begin{tabular}{|c|c|c|}
\hline \multicolumn{2}{|c|}{$\begin{array}{c}\text { Data do apparecimento da reacção "positiva" } \\
\text { em 3I casos de syphilis }\end{array}$} & \\
\hline $\begin{array}{l}\text { N. }{ }^{\circ} \text { de dias depois do } \\
\text { accidente primario }\end{array}$ & $\begin{array}{l}\text { N. de casos } \\
\text { positivos }\end{array}$ & \\
\hline 5 & 1 & \\
\hline 8 & 2 & \\
\hline 11 & 2 & \\
\hline 13 & 3 & \\
\hline 14 & 1 & \\
\hline 17 & 2 & \\
\hline 18 & 2 & \\
\hline 19 & 2 & \\
\hline 20 & 1 & \\
\hline 21 & 2 & \\
\hline 23 & 1 & \\
\hline 25 & 2 & \\
\hline 30 & 6 & \\
\hline
\end{tabular}

(*) Extraído do "Séro-diagnostic de la syphilis" Noguchi. "Monographies cliniques" 
Temos, por conseguinte, 97 a $80 \%$ de resultados que, em nada ajudam ao clinico, mas que, pelo contrario, podem trazer embaraços aos menos conhecedores do assumpto.

No periodo secundario, isto é, no periodo das papulas, o resultado da reacção é mais ou menos constante e podemos obter a porcentagem de 96 a $98 \%$ ou talvez, com muita felicidade, $100 \%$ de resultados positivos, havendo ainda, quasi sempre, na melhor das hypotheses, uns 2 a $4 \%$ de resultados falhos. No periodo terciario ou das inflammações, a porcentagem é mais ou menos identica.

Casos ha, porém, em que a syphilis passa desappercebida syphilis latente e, nesses casos, vamos obter uma porcentagem de resultados positivos, muito menor, isto é, de 25 a $62 \%$.

I'orque essa tão grande diversidade dos resultados da reacção de Wassermann, excluindo todos os outros factores de que falaremos mais adeante e que são tambem causa de erro, induzindo-nos a resultados falsos?

Só se o pode explicar, pelo que ficou dito acima, isto é, que a infeção hunteriana não determina em todos os organismos, as mesmas reacções de immunidade, talvez.

Como obviar a este inconveniente, para se poder obter maior numero de positivos nos resultados da Wassermann, feita com sôro de doentes, clinicamente syphiliticos, nos não achando expostos a grandes distanceios da verdade?

Meio seguro, não n-o conhecemos até agora, porém, podemos tentar, nos casos já um tanto velhos, e temos obtido algums resultados satisfatorios, fazer a reactivação do procèsso, injectando-se saes de mercurio, e repetindo-se o exame 8 a 15 dias após.

Outro factor importante que, não raras vezes, falseia o resultado da reaç̧ão de Wassermann, é o antigeno, pois, todos nós sabemos que, nesta reaç̧ão, ao contrario do que se passa para as outras que têm por base, tambem o desvio do complemento, brilhantemente estudado por Bordet e Gengou, o antigeno não é especifico; nós lidamos com um anticorpo especifico e um antigeno não especifico, o que, facilmente se prova, attentando para o processo de que os diversos laboratorios usam na sua confecção: uns, fazem-n-o de coração de boi, outros, de coração humano; outros, de figado de féto hererlo-syphilitico; outros, de fécula de batata; outros, de lipoides va- 
rios, etc., etc. Ora, é claro que um antigeno não especifico póde entrar em combinações com outros anticorpos que não o syphilitico e, dahi, o não termos uma reacção que se possa chamar de especifica, pois, de facto, a reacção de Wassermann ¿á resultados positivos em varias outras affecções, como na lepra, na escarlatina, nas tripanosomiases e, em fraco gráu, nas anemias intensas, etc.

Convém deixar aqui, entre parenthesis, um esclarecimento sobre a positividade da reacção de Wassermann nos casos de cancer visceral: alguns autores acham que seja ella dependente da affecção mesma, porém, um experimentador inglez, cujo nome me não recorda, estudando a questão, chegou ao seguinte resultado: os doentes syphiliticos são mais frequentemente, atacados desse mal, que os individuos não portadores do mal de Lües e que, em doentes de cancer, com um passado não syphilitico e sem apresentar, clinicamente, os estigmas da syphilis, a reação, apesar da existencia do carcinoma, continúa negativa, a não ser que o doente já se apresente cachetico, como é muito commum, dando, então, a reaç̧ão levemente positivo.

Qual o meio de que dispômos para evitar esse engano, muitas vezes, desastroso da Wassermann, impedindo resultado positivo em casos que não sejam de syphilis?

Os nossos hodiernos conhecimentos nos não permittem algo de positivo" sobre este ponto. $O$ mais que actualmente se faz nos laboratorios é usar mais de um antigeno na confeç̧ão da Wassermann, porém, os resultados obtidos são tão mesquinhos que mal pagam o trabalho que se toma em os empregar. Esperamos que, com o se generalizar do emprego do antigeno feito com culturas de Treponemas, bastante se melhore o processo da reacção, podendo-se, então, falar de uma reacção especifica.

Este modo de preparação de antigeno, experimentado pela primeira vez por Noguchi, em abril de 1912 , deu resultado satisfactorio, pois, permittiu, nas mãos deste grande sabio, augmentar muito a porcentagem de positivos em casos de syphilis segundaria e terciaria e em coelhos innoculados experimentalmente.

Craig e Nichols, repetindo esses trabalhos, notaram que as reacções feitas com tal antigeno apresentavam-se mais fracas do que quando o antigeno usado era feito com lipoides. 
Ḳohner, Williams e Laubaugh obtiveram com o antigeno feito de cultura de Treponema pallidum, reaç̧ões bem claras e com grande porcentagem de positivos.

Zinsser e Hopkins, levados pelos resultados obtidos por Noguchi e outros, na reacção de Wassermann com o antigeno de cultura de syphilis, tentaram, com resultado, a agglutinação dos Treponemas pelas agglutininas do sangue de lïeticos e de coelhos innoculados experimentalmente.

O processo de preparação do antigeno com cultura deveria ser largamente usado, porém, apresenta uma difficuldade enorme, constituindo mesmo,- hoje, barreira ao seu emprego é o ser demasiado difficil cultivarem-se taes germens.

A agglutinação é uma prova que se não devia desprezar, porém, lutaremos com os mesmos embaraços e talvez maiores que para a preparação do antigeno, pois, precisariamos um meio mais rapido e accessivel de culturas dos Treponemas.

Temos fé que, futuramente, com o proseguir dos estudos sobre a syphilis e seu agente causador e sobre as reações do organismo nesta affeção, se possa, mais scientificamente explicar o como se processa, qual o mecanismo intimo da reação de Wassermann e, disto, possamos tirar vantagens quer facilitando quer dando maior segurança aos resultados desta reaç̧ão e, conseguintemente, ao diagnostico da infeç̧ão hunteriana.

Ontro factor ainda, que pode contribuir para falsear os resultados da reaç̧ão, em que isto pareça irrisorio, é o factor pessoal: nem todos os analystas usam do mesmo rigor na te(hnica e leitura da reaç̧ão e cada qual quer usar os processos mais faceis de se obter reaç̧ão, não se preoccupando muito com a maior ou menor segurança dos resultados. Haja vista os liversos processos de technica que os experimentadores aconselham e as multiplas modificações que se ha introduzido na technica da Wassermann, desde o processo primitivo até os rossos dias e, para provar a veracidade do que affirmo, está ahi, patentemente, a reação de Landau que, por muito boa, foi posta á margem.

Lma outra prova é a immensa quantidade, ou melhor, a elevada porcentagem de positivos que obtêm os analystas que iniciam sua aprendizagem da Wassermann, quer porque sejam 
victimas da inagilidade de suas mãos, não medindo exactamente os elementos que entram na reacção, quer porque, por falta de habito da leitura da reaç̧ão, achem ou tenham propensão para os resultados positivos que são, quasi sempre, indiscutidos e indiscutiveis.

Sanadas as causas do erro que nossos actuaes conhecimentos sobre a Wassermann nos revelaram e nos permittiram corrigir, ainda a reacção de Wassermann é, em grande parte, de resultados pouco satisfatorios e, muitas vezes, induz aos desprevenidos, a diagnosticos erroneos e de consequencias desastrosas.

Durante a nossa estadia no Laboratorio da Santa Casa, vimos fazendo, de 1913 a esta data, sob a direcção scientifica do illustre mestre, o dr. Alex. Pedroso, cujos ensinamentos, com grande gaudio, hemos muito aproveitado e, a quem, aproveitando o ensejo que ora nos apresenta, deixamos aqui, os nossos agradecimentos e respeitos, vimos fazendo, diziamos, de 1913 a esta parte, 9.516 reaç̃ões de Wassermann, para esclarecimento de diagnosticos, quer em casos suspeitos de syphilis, quer em casos que nos foram enviados sem se haver, clinicamente, notado manifestação syphilitica e, por isso. para excluir esta hypothese. Nesses nove mil e poucos casos, apesar de usarmos de tres antigenos differentes, isto é, preparados de substancias diversas, apesar de seguirmos uma technica rigorosa, sobre que falaremos em um dos proximos numeros da Revista, apesar de, na leitura da reacção, não sermos tão brandos e usando do maximo rigor que a acurada pratica de nosso já citado mestre nos permittia, apesar de empregarmos complemento extrahido de varias cobayas para evitar as grandes oscillações de dosagem, apesar de tudo isto, obtivemos uma porcentagem de 68 a $72 \%$ de resultados positivos.

Mostra-nos isto que, em 28 a $32 \%$ de resultados obtidos, não podemos, com seguranģa, garantir que se não trate de doentes syphiliticos e isto por que?

Não pela falta de cuidado, não pelo desconhecer dos aper feiçoamentos da reação, mas, porque nossos actuaes conhecimentos sobre esta reação cujo mecanismo intimo ninguem actualmente conhece, nos não permittem garantir categoricamente que o resultado que damos seja absoluto ou infallivel. 
A reacção de Wassermann, já bastante conhecida, até entre os leigos, presta, em muitos casos, relevantes serviços ao clinico e não devemos deixar de a ouvir desde que possamos para ella, appellar, pois, é um auxiliar valioso, quer confirmando diagnosticos, quer esclarecendo outros, quer infirmando-os: dae a Cesar o que é de Cesar, diz o adagio, não sejamos nem tão apologistas da reaç̧ão de Wassermann, nem n-a desprezemos como coisa inutil e de valor mediocre.

Transcreverei para aqui, uma phrase proferida pelo emerito prof. o Dr. Rubião Meira, em uma aula de clinica na Santa Casa, em 1911, discorrendo sobre o valor da reàçãa de Wassermann :

"O seu valor é, senhores, dubio, como muita coisa em Medicina: - importante quando positiva, retirando hesitações, confirmando diagnosticos, infirmando outros, mas, sem preço quando negativa, porque provoca as mesmas duvidas, origina as mesmas vacillações no espirito do clinico". 